\title{
VARIABILIDADE ESPAÇO-TEMPORAL DA BIOMASSA FITOPLANCTÔNICA E HIDROLOGIA NO ESTUÁRIO DO RIO UNA (PERNAMBUCO - BRASIL)
}

\author{
Rafaella Brasil BASTOS ${ }^{1}$ \\ Fernando Antônio do Nascimento FEITOSA ${ }^{2}$ \\ Kátia MUNIZ ${ }^{2}$
}

1-Departamento de Oceanografia da UFPE/ Bolsista CNPq - rafaellabb@hotmail.com 2-Professor adjunto do Departamento de Oceanografia da UFPE

\author{
Recebido: 04/04/04 \\ Aceito: 20/12/04
}

\section{RESUMO}

Com o intuito de caracterizar e diagnosticar o estuário do rio Una através da análise da comunidade fitoplanctônica e dos parâmetros ambientais se desenvolveu esta pesquisa. As amostras foram coletadas, em sua maioria, na superfície com garrafa de Nansen, em três pontos fixos, durante a baixa-mar e preamar diurna, em maré de sizígia. A pluviometria total anual foi de $1319,5 \mathrm{~mm}$; a transparência da água variou entre 0,20 e $2,25 \mathrm{~m}$; a temperatura entre 23,8 e $32,0^{\circ} \mathrm{C}$; a salinidade entre 0 e 39\% $\%$ aa taxa de saturação do oxigênio entre 74,8 e 132,4\%; o pH entre 7,07 e 8,93; o nitrito de valores indetectáveis a $0,37 \mu \mathrm{mol} . \mathrm{L}^{-1}$; o nitrato de 0,05 e $14,70 \mu \mathrm{mol} . \mathrm{L}^{-1}$; o fosfato de indetectável a $0,76 \mu \mathrm{mol} . \mathrm{L}^{-1}$; o silicato de 12,99 a $476,04 \mu \mathrm{mol} . \mathrm{L}^{-1}$; o material em suspensão de 2,00 a $114,50 \mathrm{mg} \cdot \mathrm{L}^{-1}$ e a biomassa fitoplanctônica de 1,68 a 36,30 $\mathrm{mg} \cdot \mathrm{m}^{-3}$, indicando tratar-se de um ambiente eutrófico. Baseado na taxa de saturação do oxigênio dissolvido o ambiente foi caracterizado como não poluído e de acordo com a análise dos componentes principais a biomassa correlacionou-se diretamente com o material em suspensão, o nitrito, o nitrato e a pluviometria e inversamente com a transparência e o pH.

Palavras chaves: fitoplâncton, biomassa, estuário e hidrologia.

\begin{abstract}
The present work was performed in the estuary of the Una River, located in the south coast of the Pernambuco State (Brazil), at $130 \mathrm{~km}$ of the Recife City. The objective of this work was to characterize and to diagnosis the cited ecosystem through the phytoplankton community and the hydrological parameters. The water samples had been collected in the surface through Nansen bottles, at three fixed stations during the low and high tide. The total rain was $1,319.5 \mathrm{~mm}$; the water transparency varied from 0.20 to $2.25 \mathrm{~m}$; the temperature from 23.8 to $32^{\circ} \mathrm{C}$; the salinity from 0 to $39 \%$; the oxygen saturation rate from 74.8 to $132.4 \%$; the $\mathrm{pH}$ from 7.07 to 8.93 ; the nitrite of indetectable values to $0.37 \mu \mathrm{mol} . \mathrm{L}^{-1}$; the nitrate from 0.05 to $14.70 \mu \mathrm{mol} . \mathrm{L}^{-1}$; the phosphate of indetectable values to $0.76 \mu \mathrm{mol} . \mathrm{L}^{-1}$; the silicate from 12.99 to $476.04 \mu \mathrm{mol} . \mathrm{L}^{-1}$; the suspended matter from 2.0 to $114.50 \mathrm{mg} . \mathrm{L}^{-1}$; the phytoplankton biomass from 1.68 to $36.30 \mathrm{mg} . \mathrm{m}^{-3}$ showing a eutrophic condition. The oxygen saturation rate the ecosystem as characterized not polluted. The principal analysis components showed that the phytoplankton biomass was directly correlated with
\end{abstract}


the suspended matter, nitrite, nitrate and rain and inversely correlated to the water transparency and $\mathrm{pH}$.

Key words: phytoplankton, biomass, estuary and hidrology.

\section{INTRODUÇÃO}

Os estuários são ambientes costeiros bastante complexos devido ao seu forte hidrodinamismo sofrendo grandes alterações nos seus parâmetros hidrológicos e biológicos.

Estes ambientes vêm sofrendo impactos diversos, tais como aterros, degradação e poluição, causando uma diminuição da biodiversidade e, conseqüentemente, de seus recursos alimentícios. Todos esses impactos causam grandes conseqüências tanto para a biota local como também para o ser humano.

A preservação desses ambientes é de vital importância, pois, além de servirem como área de alimentação, berçário, habitat, refúgio e reprodução de varias espécies, são grandes produtores de alimentos para o homem e muitas famílias retiram seu sustento desses ecossistemas.

São consideradas áreas altamente produtivas, tanto em função da grande disponibilidade de sais nutrientes como em função da presença de vários produtores primários, destacando-se dentre estes a comunidade fitoplanctônica. Entretanto, esta comunidade sofre variações diurnas em sua composição especifica, biomassa, densidade e produtividade provocadas pelo fluxo e refluxo das marés. As variações sazonais também são comuns nessa comunidade, e em regiões tropicais a amplitude e periodicidade dessas variações dependem quase exclusivamente do regime de chuvas. Diferenças sazonais nas descargas dos rios provocam alterações nos valores de salinidade e nas condições quali-quantitativas do fitoplâncton (SOURNIA, 1969).

Tendo em vista a importância do estuário do rio Una no contexto da pesca artesanal para o litoral sul do Estado de Pernambuco, pretendeu-se avaliar a influência deste estuário na zona costeira adjacente tendo como objetivo principal caracterizar e diagnosticar o referido ambiente através da comunidade fitoplanctônica e dos parâmetros ambientais.

\section{MATERIAL E MÉTODOS}

O rio Una apresenta cerca de $200 \mathrm{~km}$ de extensão desde a nascente até a sua foz, tendo a sua bacia hidrográfica uma área de $5.906 \mathrm{~km}^{2}$ correspondente a 6,01\% da área do Estado de Pernambuco (CONDEPE, 1980).

Segundo a classificação de Koppen, o clima na bacia do rio Una varia de BShs’ (próxima a nascente) a AS' (no litoral) cujas quotas pluviométricas anuais variam entre 600 a mais de $1000 \mathrm{~mm}$ e a temperatura media varia entre $26^{\circ} \mathrm{C}$ e $24^{\circ} \mathrm{C}$, respectivamente.

A área estuarina do rio Una encontra-se inserida no município de São José da Coroa Grande-PE, distante 130km do Recife, fazendo parte da Área de Proteção Ambiental (APA-Costa dos Corais). Possui em suas margens uma vegetação de mangue representada pelas espécies Rhizophora mangle L., Laguncularia racemosa Gaerth, Avicennia schaweriana Stapt et Lechman e Conocarpus erectus L.

Baseado no hidrodinamismo local foram estabelecidas três estações fixas (Fig.01), onde a estação 1 corresponde a foz do rio Una (costeira), a estação 2 situada a $2 \mathrm{~km}$ da foz (intermediária) e a estação 3 situada a $4 \mathrm{~km}$ da foz (interna). 


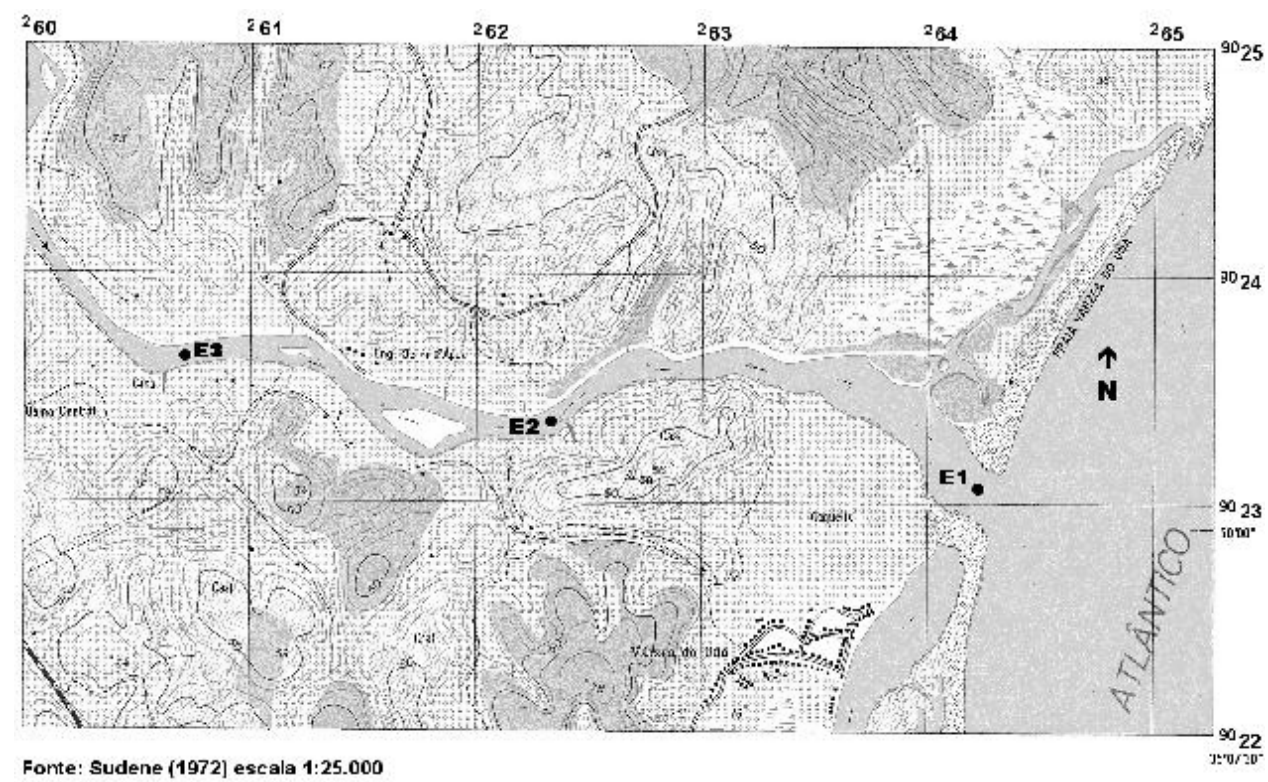

Figura 01 - Mapa da área de estudo com as estações de coleta.

As coletas de água foram realizadas mensalmente, no período de janeiro a dezembro de 2001, na superfície (exceto para a temperatura e a salinidade que foram também coletadas no fundo) durante a baixa-mar (BM) e preamar (PM) de um mesmo dia, em marés de sizígia. Os dados de pluviometria total procederam da estação meteorológica de Porto de Galinhas, distante cerca de $45 \mathrm{~km}$ da área estudada; a transparência foi medida pelo disco de Secchi; a temperatura por um termômetro comum com escala de -10 a $60^{\circ} \mathrm{C}$; a salinidade por um refratômetro da Atago; o teor de oxigênio dissolvido e sua taxa de saturação de acordo com Strickland e Parsons (1972) e tabela da UNESCO (1973); o pH pelo pHmetro; os sais nutrientes (nitrito, nitrato e fosfato) pelo método de Strickland \& Parsons (1972) e o silicato pelo método de Grasshoff et al (1983); o material em suspensão pelo método de Melo et al. (1975); e a biomassa fitoplanctônica através do método espectrofotométrico de Parsons e Strickland (1963), descrito pela UNESCO (1966).

\section{RESULTADOS}

De acordo com os dados pluviométricos obtidos no período estudado (janeiro a dezembro/01), verificou-se que o período chuvoso tendeu a acompanhar a curva dos onze anos (1991 a 2001) de dados coletados, com exceção dos meses de abril, maio, julho e setembro. Dentre os meses do período chuvoso abril apresentou $64,71 \%$ da média histórica mensal; maio 4,09\%; julho $79,90 \%$ e setembro $28,00 \%$. Em relação ao total anual de chuvas verificou-se que o ano de 2001 apresentou um total de 1.319,5mm, estando assim, abaixo da média de onze anos, ultrapassando apenas os anos de 1993, 1998 e 1999 (Fig. 02 e 03). 


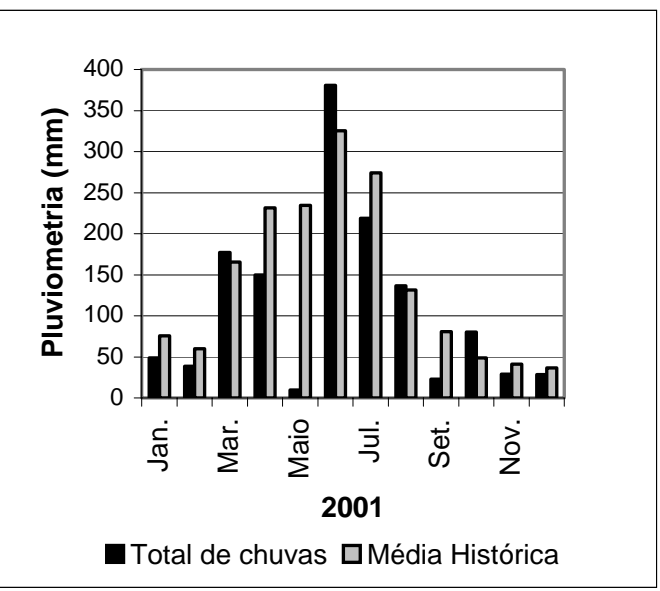

Figura 02 - Total mensal (2001) e média histórica mensal de chuvas (1990-2001).

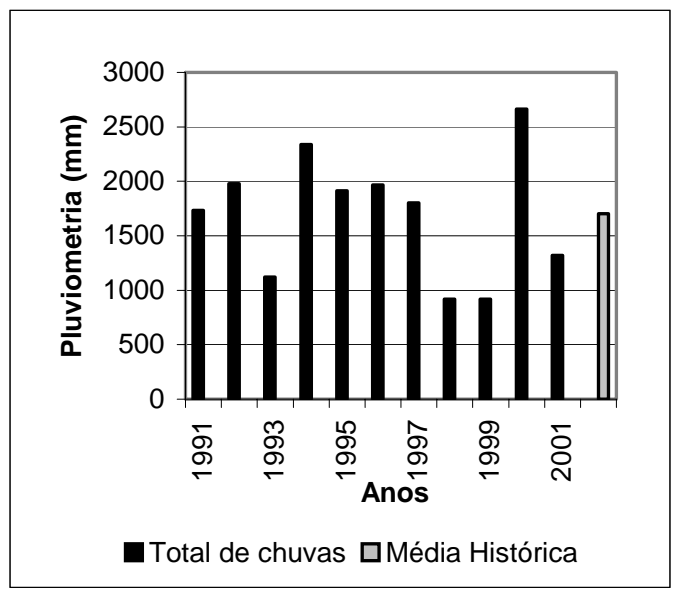

Figura 03 - Total de chuvas anual e média histórica.

A transparência da água apresentou um padrão sazonal definido em ambos regimes de maré, atingindo os maiores valores no período de menor precipitação pluviométrica. Quanto à variação espacial, a transparência da água variou da estação 1 a 3, tanto na baixa-mar como na preamar, sendo a estação 3 a de menor transparência na maioria dos meses (Fig. 04). Durante a preamar verificou-se um gradiente decrescente da estação 1 para a estação 3 , exceto nos meses de abril, maio e agosto. A transparência da água variou de $0,20 \mathrm{~m}$ na estação 3 na baixa-mar e preamar do mês de julho à 2,25m nas estações 1 e 2, na preamar do mês de dezembro.

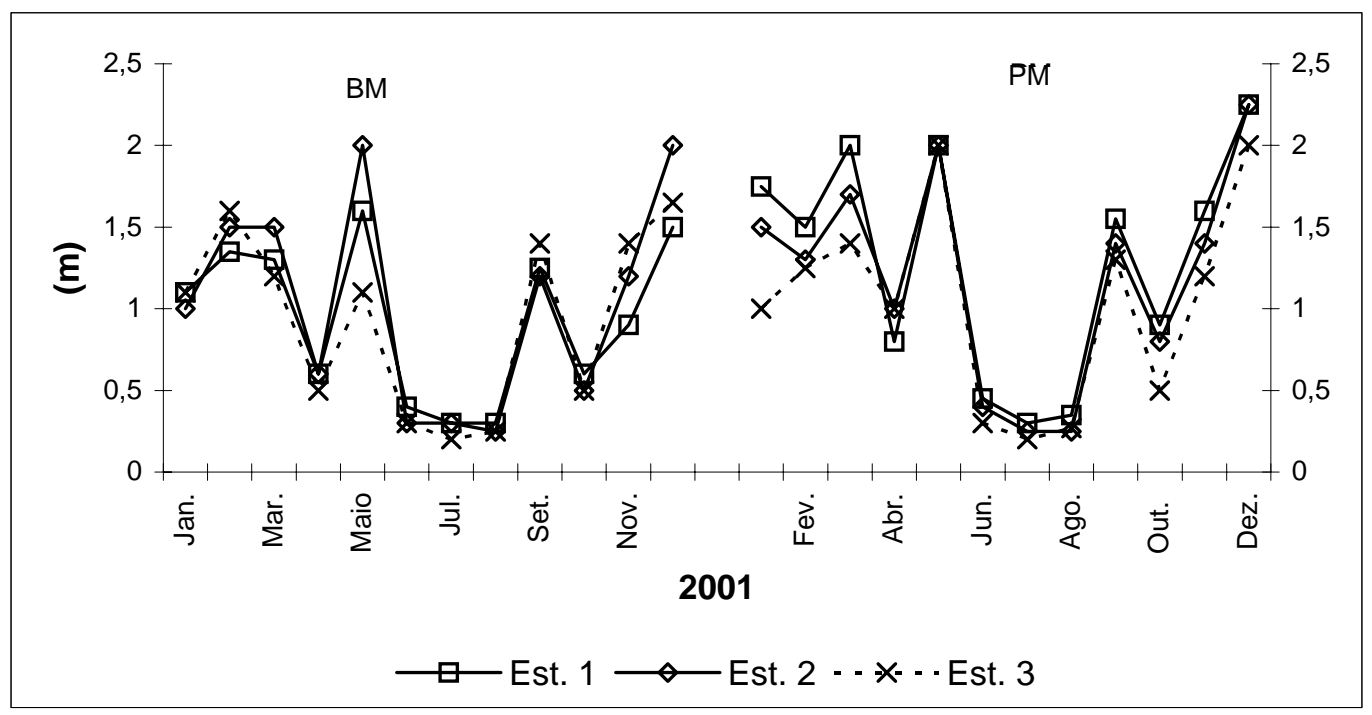

Figura 04 - Variação espacial e temporal da transparência da água no estuário do rio Una. 
A temperatura da água apresentou um discreto padrão sazonal, com menores valores no período de maior precipitação pluviométrica. Não foi observada grandes diferenças entre a superfície e o fundo do estuário, demonstrando não haver uma estratificação térmica no ambiente. Também não foi observada uma variação espacial significativa (Fig. 05). A temperatura variou de $23,8^{\circ} \mathrm{C}$ à $32,0^{\circ} \mathrm{C}$ na estação 2 nos meses de agosto na superfície durante a baixa-mar e fevereiro na superfície durante a preamar, respectivamente.
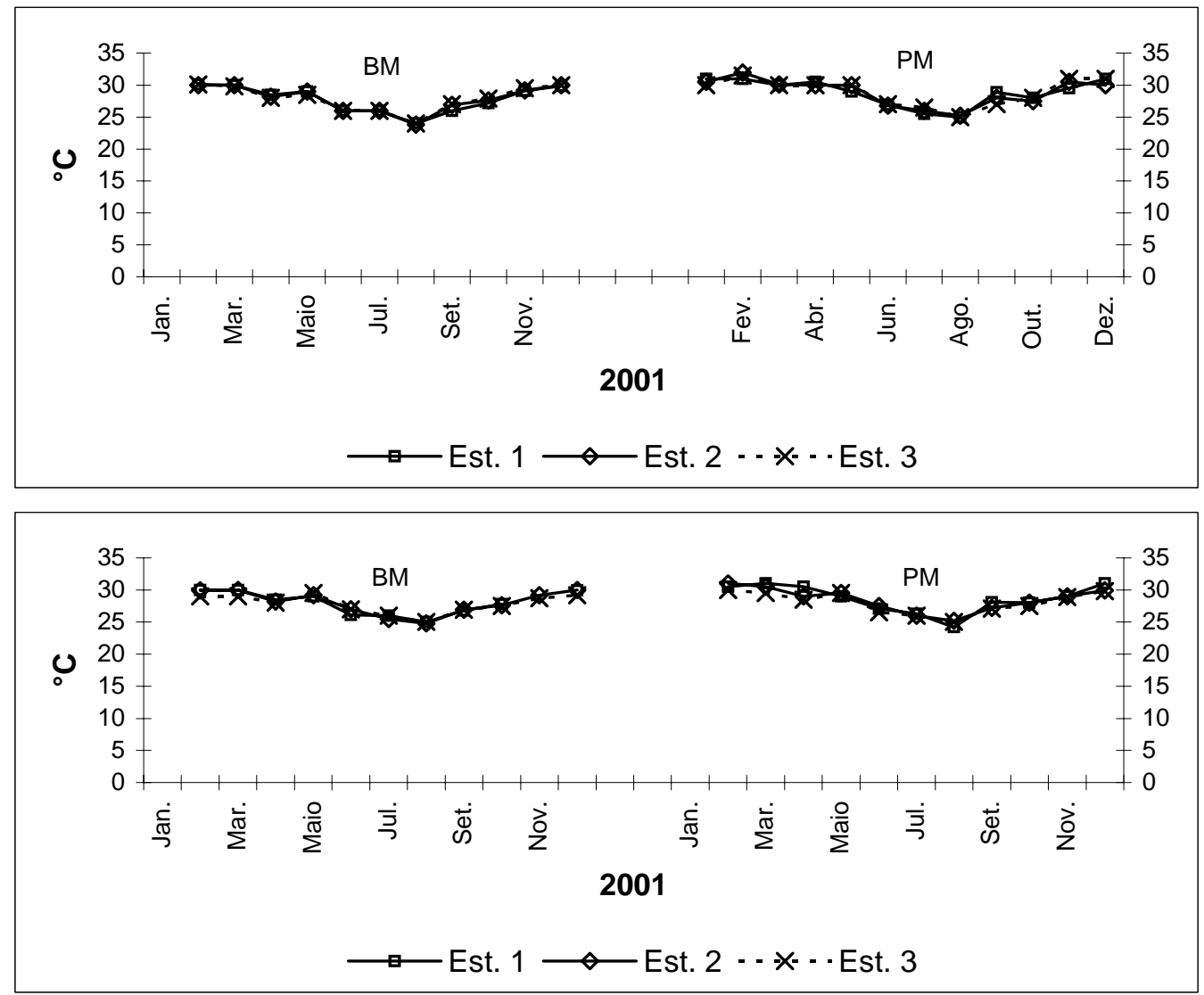

Figura 5 - Variação espacial e temporal da temperatura da água na superfície e fundo, respectivamente no estuário do rio Una.

Foi observada uma nítida variação sazonal na salinidade com maiores teores no período seco, tanto na superfície como no fundo em ambos os regimes de maré. Do ponto de vista espacial, verificou-se que o teor de salinidade na superfície mostrou um gradiente decrescente da estação 1 para a estação 3, tanto na preamar como na baixa-mar, embora em alguns meses do período chuvoso eles tenderam a se igualar (Fig. 06). Fato importante a mencionar, é que o ambiente estudado mostrou tanto uma variação espacial quanto uma estratificação salina, pois a estação 3 apresentouse verticalmente estratificada nos meses de estiagem e verticalmente homogênea nos meses chuvosos. Na estação 2, predominou a estratificação salina na maioria dos meses, exceto em julho e agosto. Na estação 1, a estratificação salina predominou durante a preamar, enquanto que na baixamar esta estratificação foi observada nos meses de estiagem. O menor teor de salinidade encontrado foi de $0 \%$ presente nas estações 2 e 3 durante a baixa-mar em diferentes profundidades e em ambos regimes de maré, enquanto o maior foi de $39 \%$ obtido na estação 1 , no mês de maio, na superfície e no fundo, durante a preamar. 


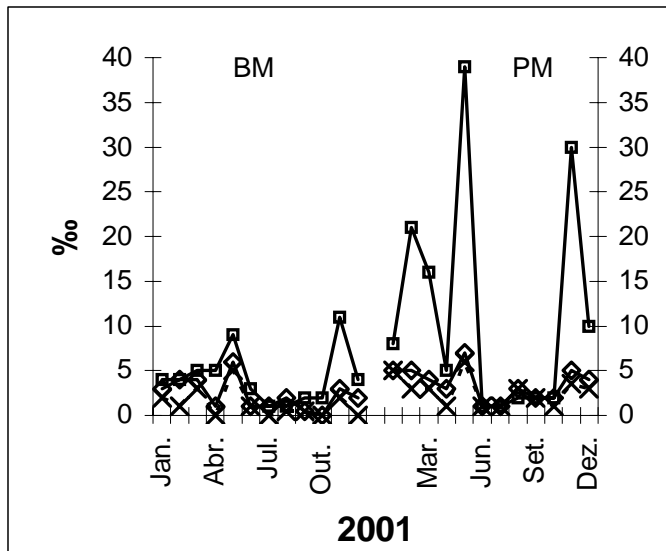

$\longrightarrow$ Est. $1 \longrightarrow$ Est. 2 - - - - - Est. 3

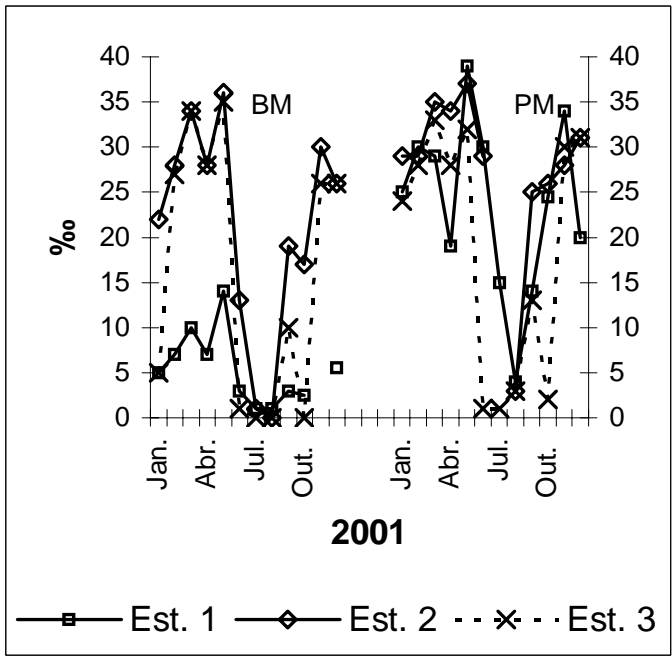

Figura 06 - Variação espacial e temporal da salinidade na superfície e fundo, respectivamente no estuário do rio Una.

A taxa de saturação do oxigênio dissolvido na água também apresentou uma certa sazonalidade com valores maiores no período chuvoso, principalmente na baixa-mar. Espacialmente, verificou-se que ocorreram diferenças entre as estações amostradas (Fig. 07). Na zona estuarina do rio Una observou-se que a menor taxa foi de $74,8 \%$ na estação 2, em março, durante a baixa-mar, enquanto a maior foi de 132,4\% na estação 2 em novembro na preamar.

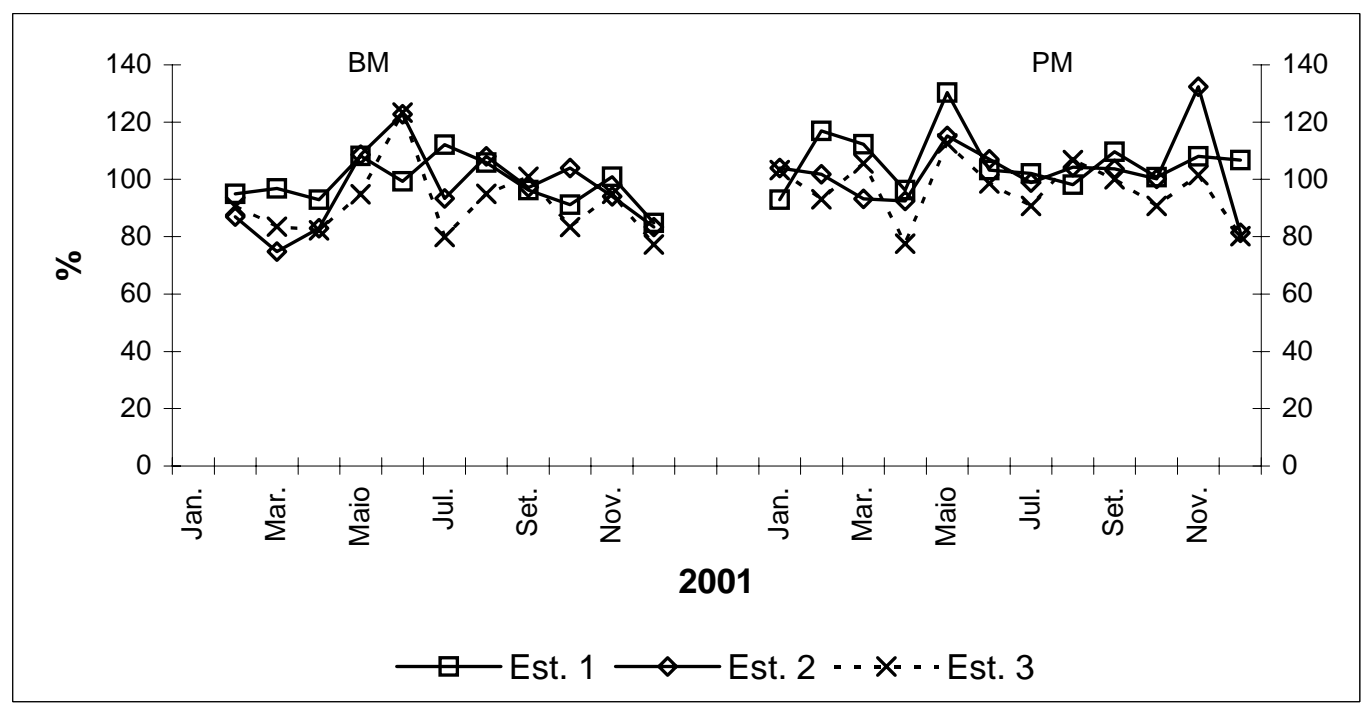

Figura 7 - Variação espacial e temporal da taxa de saturação do oxigênio dissolvido no estuário do rio Una.

Tropical Oceanography, Recife, v. 33, n. 1, p. 1-18, 2005. 
O pH esteve sempre alcalino na área estudada, não sendo observada variação espacial nem temporal. Em relação aos diferentes regimes de maré verificou-se que quase não houve diferença de pH. O mínimo obtido foi de 7,07 em outubro/01 na estação 3 na preamar e o máximo de 8,93 na estação 3 na baixa-mar (Fig. 08).

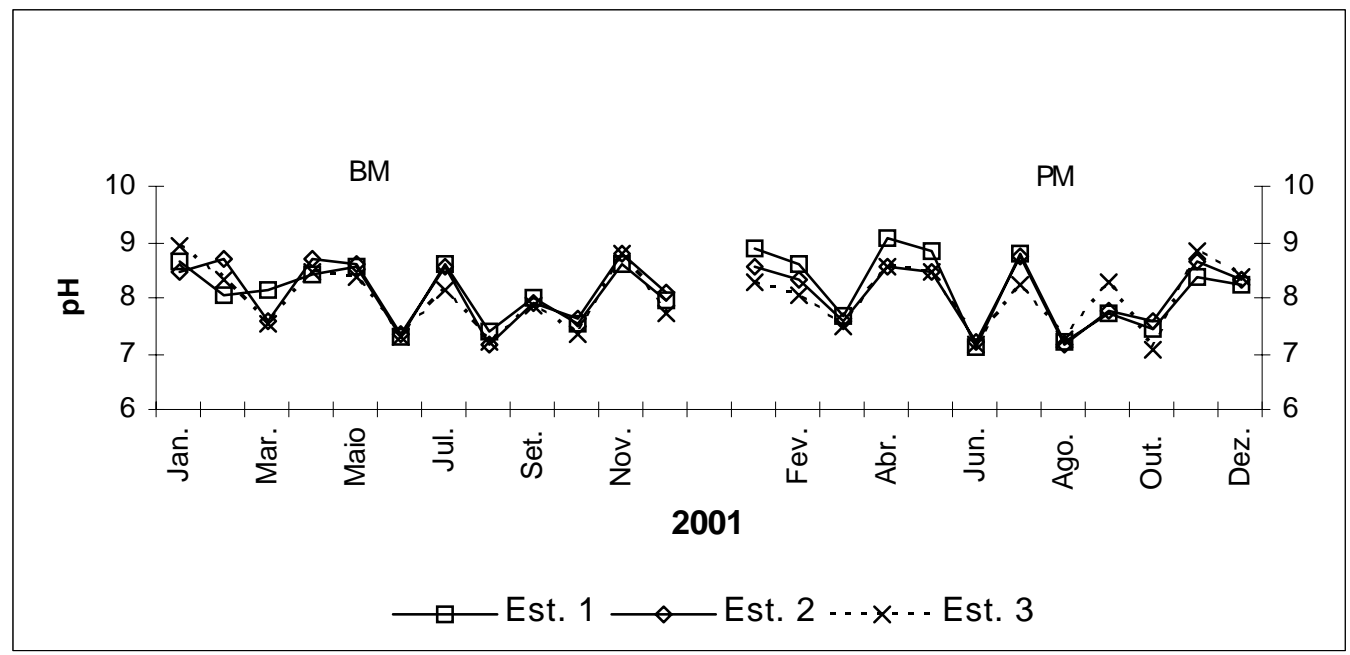

Figura 8 - Variação espacial e temporal do potencial hidrogeniônico no rio Una.

Os teores de sais nutrientes, em geral apresentaram valores elevados destacando-se o silicato como o que apresentou maior concentração seguido pelo nitrato, fosfato e nitrito. Do ponto de vista espacial observou-se uma certa variação das concentrações destes sais em relação aos três pontos amostrados. Considerando os diferentes regimes de maré praticamente não se observou diferenças significativas. Levando-se em consideração a sazonalidade o silicato apresentou-se mais concentrado durante o período seco ao contrário do nitrato e nitrito que se apresentaram mais concentrados no período chuvoso, enquanto o fosfato não apresentou variação (Fig. 09, 10, 11 e 12). A menor concentração de nitrito variou de indetectável na estação 2, no mês de novembro durante a baixa-mar e a maior de $0,37 \mu$ mol. $L^{-1}$ no estação 2 no mês de julho durante a preamar. Já o nitrato variou entre 0,05 na estação 1 no mês de maio durante a preamar e $14,70 \mu \mathrm{mol}^{-1} \mathrm{~L}^{-1}$ na estação $1 \mathrm{e} 2$ durante a baixa-mar e preamar. O fosfato variou sua concentração desde indetectável nas estações 1 e 3 nos meses de fevereiro e março durante a preamar a $0,76 \mu$ mol. $L^{-1}$ na estação 3 mês de dezembro durante a preamar. O silicato apresentou concentração mínima de 12,99 na estação 1 no mês de junho durante a preamar e máxima de $476,04 \mu m o l . L^{-1}$ na estação 1 no mês de novembro durante a baixa-mar. 


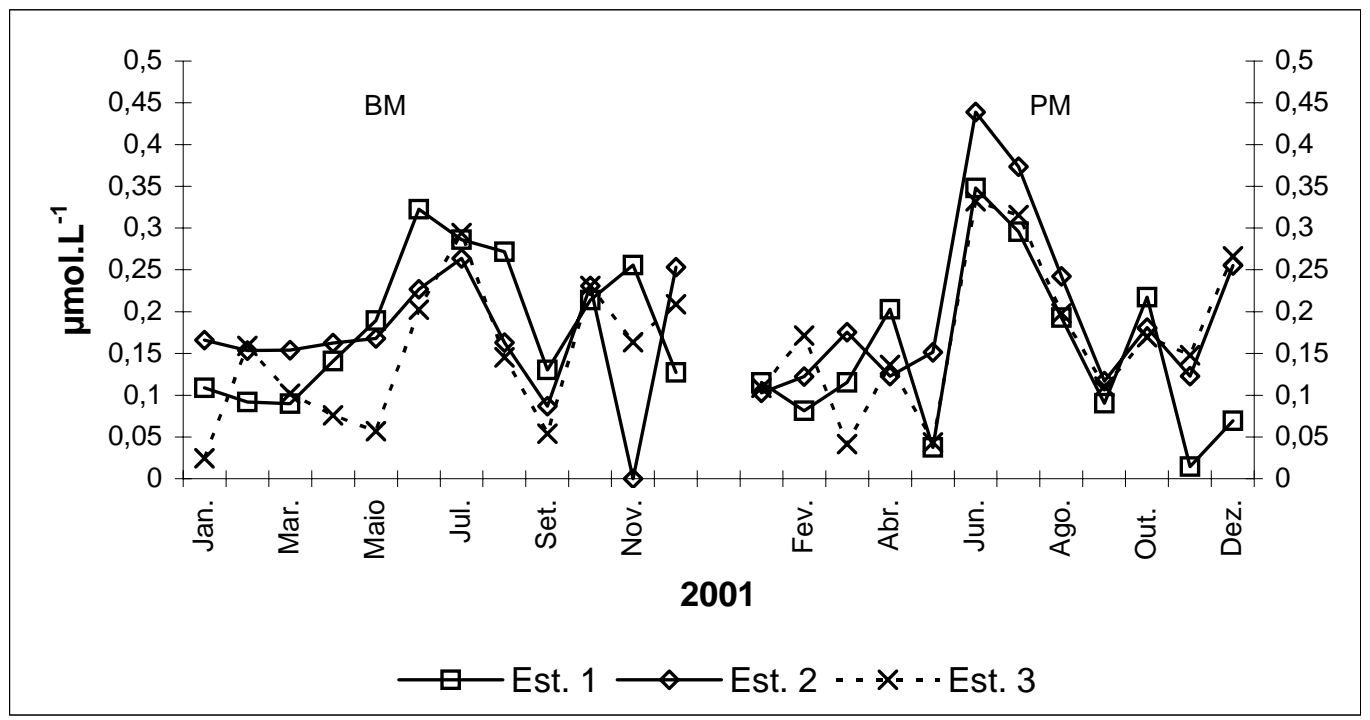

Figura 09 - Variação espacial e temporal do nitrito no estuário do rio Una.

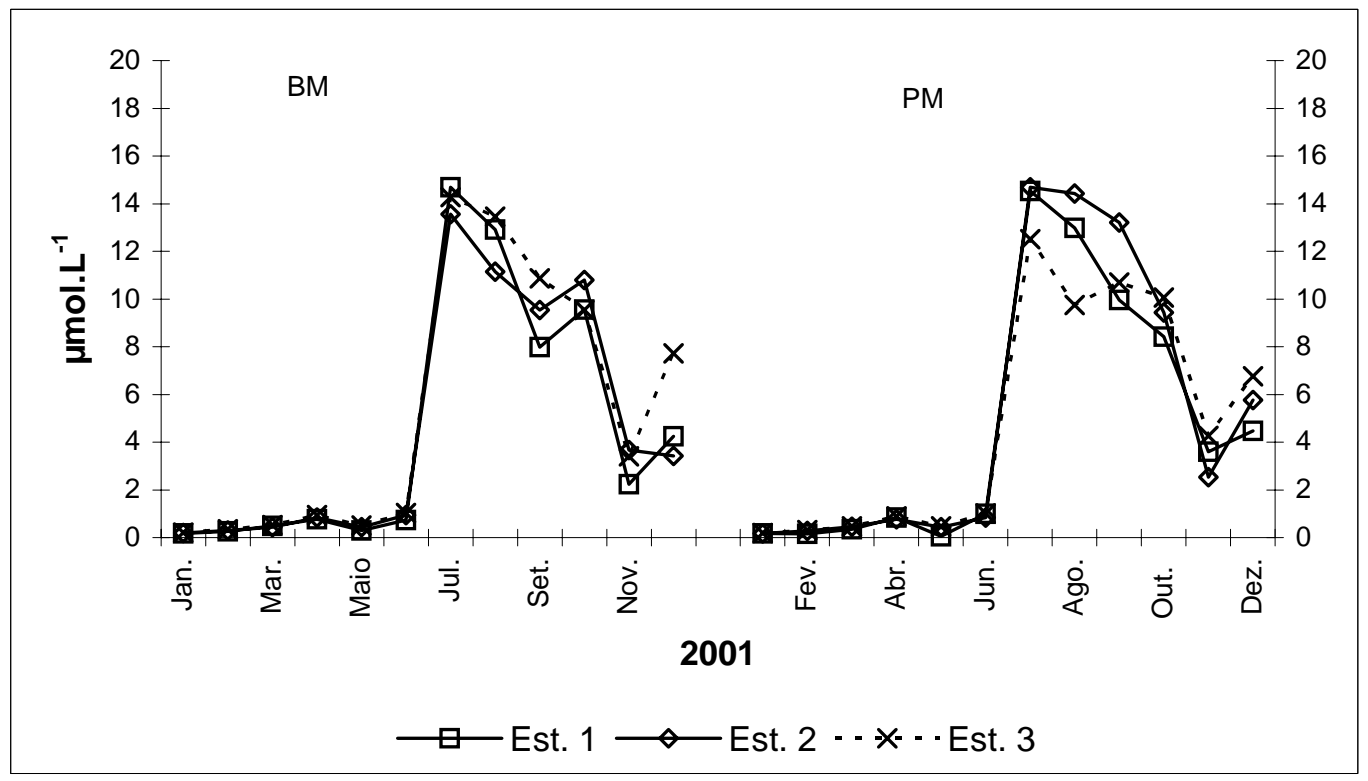

Figura 10 - Variação espacial e temporal do nitrato no estuário do rio Una. 


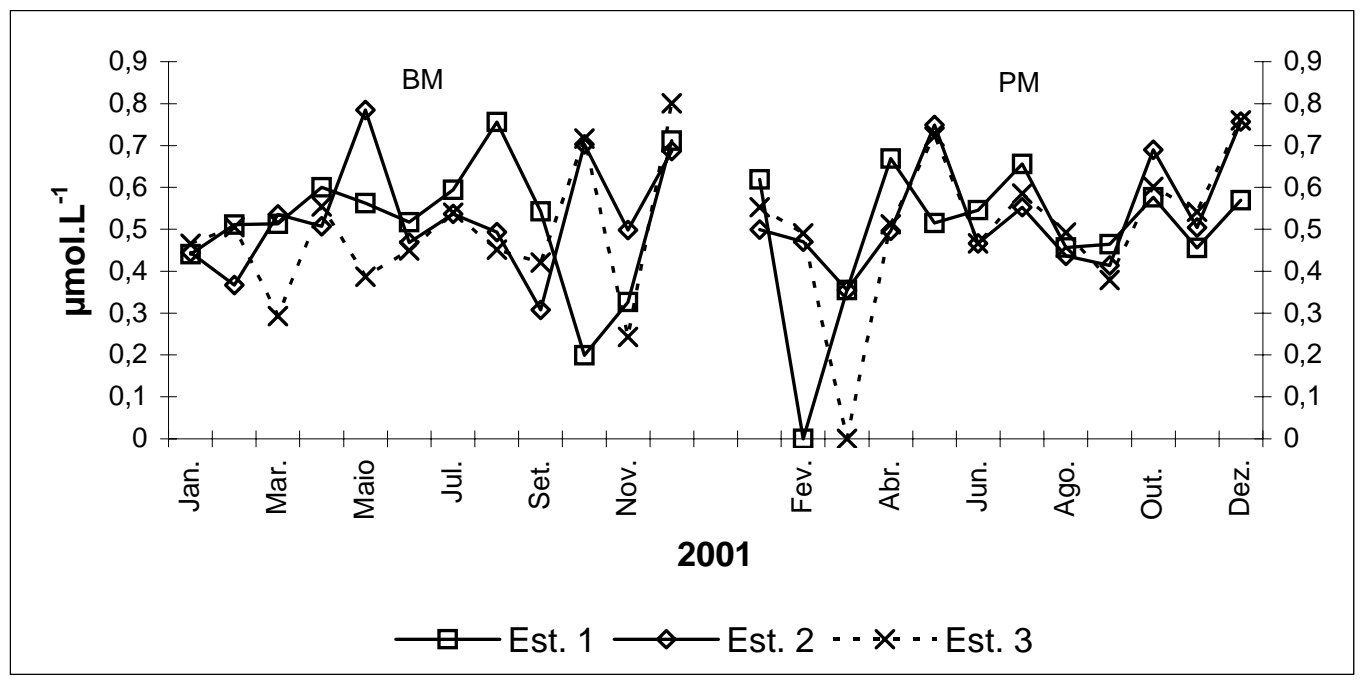

Figura 11 - Variação espacial e temporal do fosfato no estuário do rio Una.

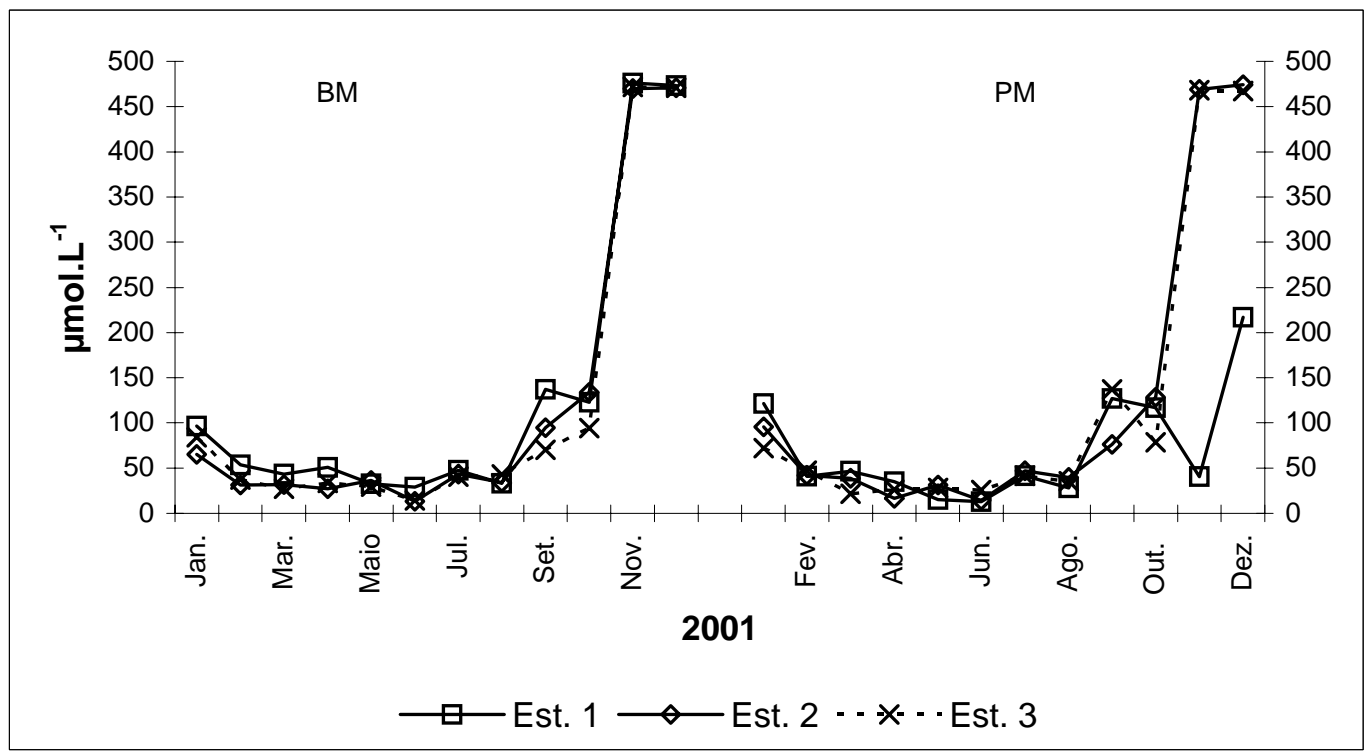

Figura 12 - Variação espacial e temporal do silicato no estuário do rio Una.

Tropical Oceanography, Recife, v. 33, n. 1, p. 1-18, 2005. 
O material em suspensão total presente na água demonstrou um padrão sazonal definido, havendo maior concentração no período chuvoso. No que se refere à distribuição espacial verificouse que houve diferença de concentração do material em suspensão entre as estações de coleta, embora não tenha ocorrido um gradiente definido (Fig. 13). No estuário do rio Una foi observado que o mínimo de material em suspensão encontrado foi de $2,00 \mathrm{mg} \cdot \mathrm{L}^{-1}$ nas três estações nos meses de janeiro, fevereiro e maio, nos dois regimes de maré e o máximo de $114,50 \mathrm{mg} . \mathrm{L}^{-1}$, na estação 1 no mês de julho, durante a baixa-mar.

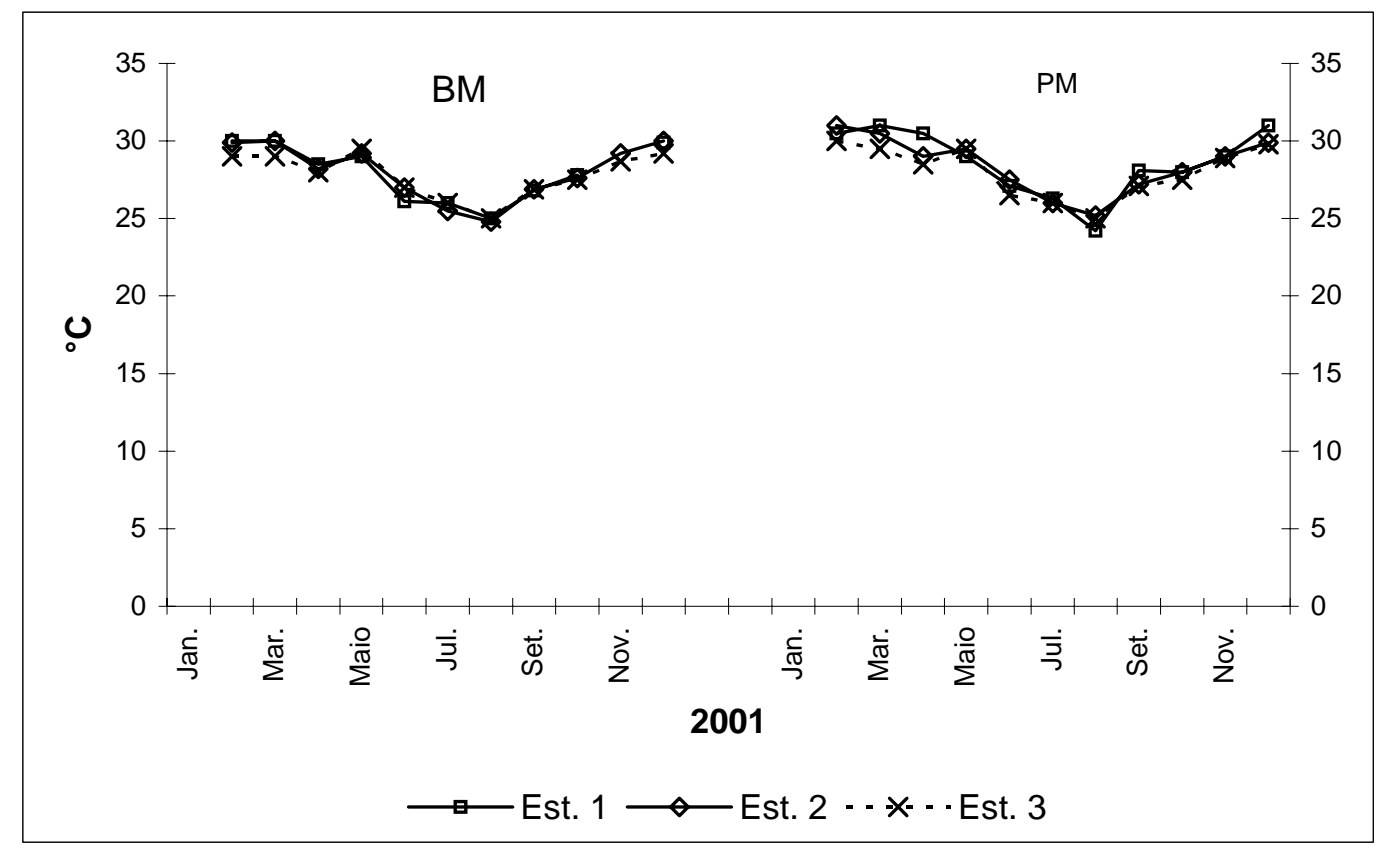

Figura 13 - Variação espacial e temporal do Material em Suspensão Total no rio Una.

A biomassa fitoplanctônica mostrou uma nítida variação sazonal no ambiente estudado, sendo os maiores valores encontrados no período em que houve uma maior incidência pluviométrica, em ambos regimes de maré. No que se refere à variação espacial observou-se uma certa diferença entre as concentrações de clorofila $a$ nas estações de coleta. Não foi possível identificar um gradiente entre as estações, uma vez que, esta variou de forma alternada (Fig.14). Em função dos valores médios da clorofila $a$ percebeu-se que a biomassa algal esteve ligeiramente mais elevada na baixa-mar. Em geral, a biomassa variou de 1,68mg.m $\mathrm{m}^{-3}$ na estação 1, em junho na baixamar à 36,30mg.m ${ }^{-3}$ na estação 2 , em agosto, na baixa-mar. 


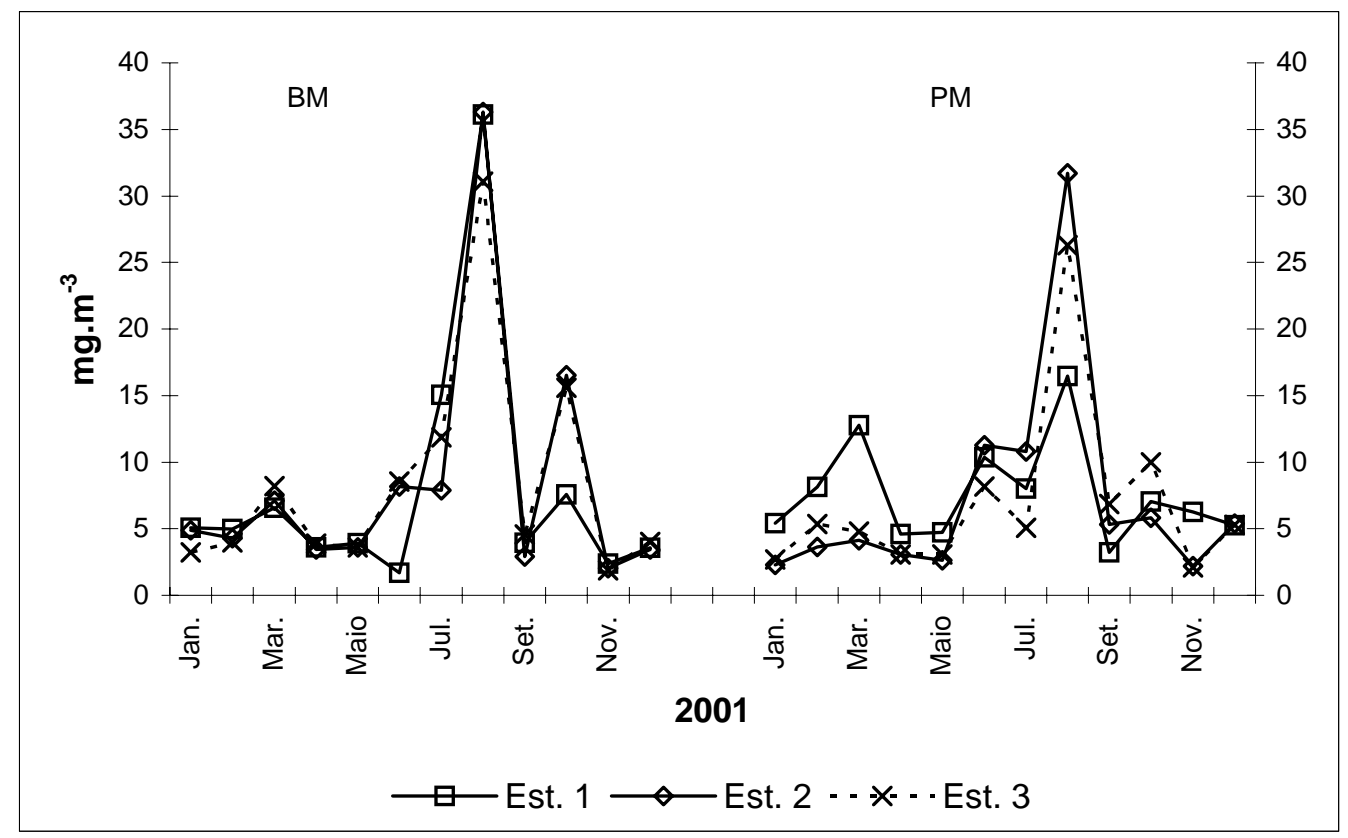

Figura 14 - Variação espacial e temporal da biomassa fitoplanctônica no estuário do rio Una.

A análise dos componentes principais (ACP) explicou 59,08\% das variações dos dados dos parâmetros analisados, o fator 1 explicou 31,23\% dos dados correlacionando diretamente a transparência da água com o potencial hidrogeniônico e inversamente com o material em suspensão total, a concentração de nitrito e nitrato, a pluviometria e a biomassa fitoplanctônica; o fator 2 explicou $15,33 \%$ das variações dos dados correlacionando diretamente a altura de maré, a temperatura e a taxa de saturação do oxigênio dissolvido e o fator 3 explicou 12,52\% dos dados correlacionando diretamente a salinidade com a concentração de oxigênio dissolvido e inversamente ao fosfato e ao silicato (Fig.15). 


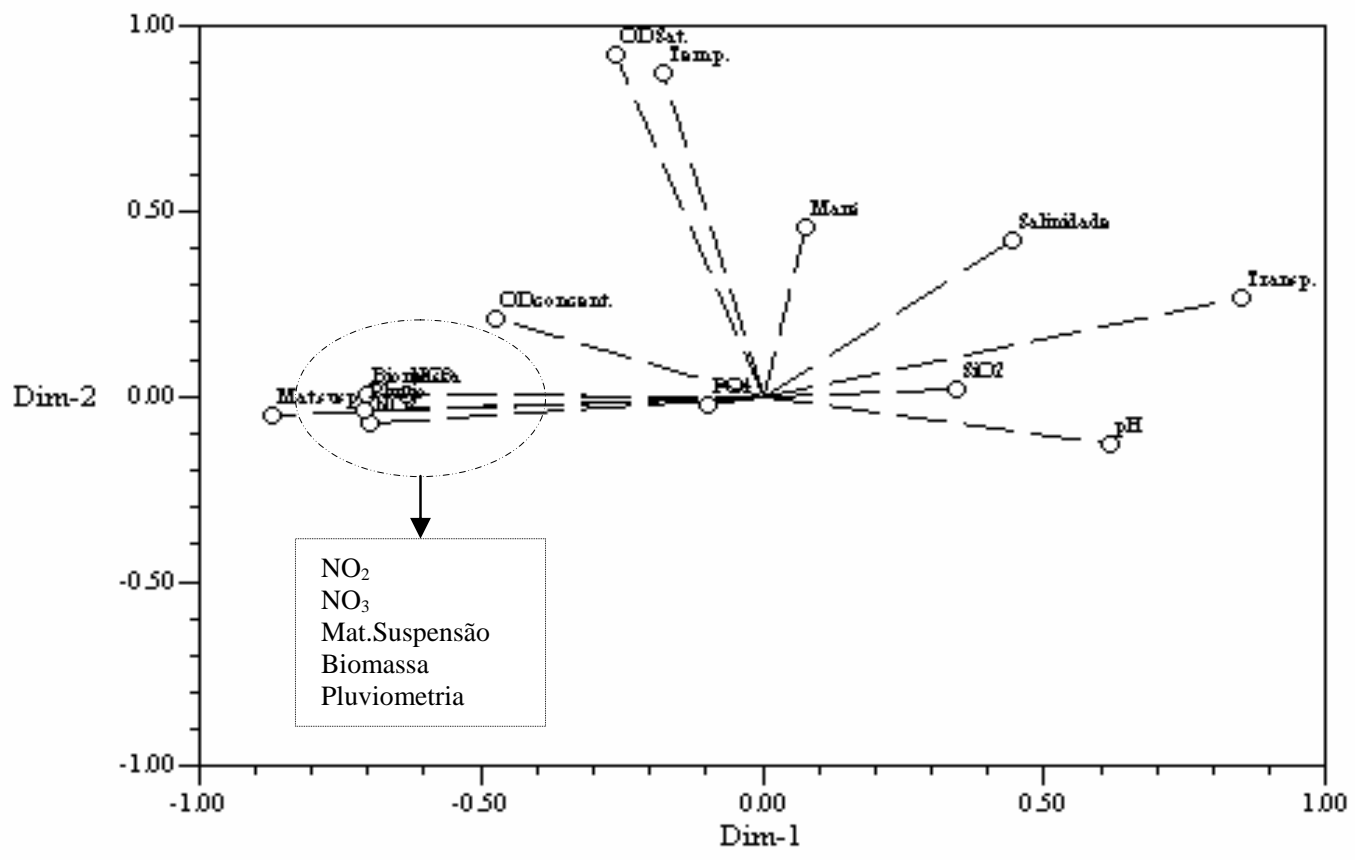

Figura 15 - Análise dos componentes principais.

\section{DISCUSSÃO}

Os principais fatores ambientais que têm fundamental importância no controle da produção primária nos ecossistemas aquáticos são os climatológicos, como o input de energia radiante e precipitação total; e, os hidrológicos, como a penetração da luz, a estrutura térmica da coluna d`água, o grau de mistura do ecossistema e o suprimento e dinâmica dos nutrientes inorgânicos (TUNDISI; TUNDISI, 1976).

De acordo com Braga (1999), os aportes de compostos dissolvidos via drenagem continental e precipitação atmosférica podem modificar temporariamente as concentrações de certas substâncias químicas na água do mar, principalmente os sais nutrientes, fornecendo condições para uma produção primária "nova” do fitoplâncton. As águas dos rios e das chuvas possuem concentrações de nitrato, nitrito, amônio, fosfato e silicato variáveis, mas freqüentemente maiores que aquelas encontradas nas águas de superfície do mar.

Particularmente, nos estuários, a precipitação pluviométrica passa a ser considerada de grande importância uma vez que, ela interfere tanto na biomassa, como na produção primária, através do aporte de sais nutrientes, assim como pela alteração da qualidade óptica da água.

Na região nordeste do Brasil, vários trabalhos realizados têm demonstrado a influência que a precipitação pluviométrica exerce sobre os parâmetros ambientais em áreas estuarinas (Passavante,1979 no Canal de Santa Cruz (PE) que verificou um aumento da biomassa algal no período chuvoso; Feitosa, 1988 na Bacia do Pina (PE), que também verificou uma forte redução da biomassa algal no período chuvoso; Santos-Fernandes, 1997 no estuário do rio Jaguaribe onde a biomassa algal aumentou no inverno, dentre outros).

Conforme o sistema de classificação de Köppen no litoral pernambucano o clima é do tipo As', ou seja, tropical quente-úmido com chuvas de outono-inverno, portanto percebeu-se que, 
durante o período estudado, foi mantido este padrão, porém, a quantidade total de chuvas ficou aquém do normal esperado para a região, ou seja, choveu 77,42\% da média dos onze anos de coleta de dados pluviométricos, muito embora, tenha sido suficiente para provocar modificações nos parâmetros ambientais.

No estuário do rio Una observou-se que a precipitação pluviométrica apresentou uma relação direta com a biomassa fitoplanctônica, material em suspensão e o teor de oxigênio dissolvido e inversa com a temperatura, salinidade e transparência da água.

Os estuários têm como uma das principais características apresentar um acentuado hidrodinamismo em conseqüência da ação das marés. Ao longo do litoral brasileiro predomina maré do tipo semi-diurna e na costa pernambucana, particularmente, com uma amplitude de aproximadamente $2,9 \mathrm{~m}$, já que a mínima é de $-0,2$ e a máxima de $2,7 \mathrm{~m}$ sendo assim, classificado como meso-maré. Devido a sua ação os parâmetros ambientais variam consideravelmente em um curto espaço de tempo. Tal padrão já foi observado em outras áreas estuarinas do litoral pernambucano (Feitosa, 1997; Losada, 2000; Branco, 2001 dentre outros). Medeiros e Kjerfve (1993) trabalhando no Canal de Santa Cruz (PE), observaram que as marés foram responsáveis pela alteração dos parâmetros hidrológicos, classificando o referido canal como bem misturado no período seco e como parcialmente misturado no período chuvoso, prevalecendo a circulação gravitacional, demonstrando assim a influência que a maré exerce neste ecossistema costeiro.

Por serem, os estuários ambientes pouco profundos e sofrerem interferência ora do rio, ora do mar, apresentam grandes variações em relação à transparência da água tendo-se como via de regra transparência com valores mais baixos durante a baixa-mar e mais altos na preamar.

No rio Una, verificou-se que a transparência da água variou tanto sazonalmente, com menores valores no período chuvoso, como em função da altura da maré, ocorrendo menores valores na baixa-mar. Esses baixos índices de transparência são compatíveis aos encontrados em outros estuários (Moreira, 1994 no estuário do rio Cocó (CE); Santos-Fernandes, 1997 no estuário do rio Jaguaribe (PE); Fernandes, 1997 no estuário do rio Congo (PE); Feitosa, 1997 no estuário do rio Goiana-PE). Teixeira et al. (1988), trabalhando na região estuarina do Estreito dos Coqueiros (MA), observaram valores muito baixos para a transparência da água, o que comprometeu consideravelmente o limite da zona eufótica, verificando os autores que houve redução drástica da biomassa fitoplanctônica com o aumento da profundidade.

A temperatura da água é um parâmetro importante dentro do ecossistema aquático, contudo, em áreas tropicais, devido a sua pequena amplitude térmica e ainda pela sua mudança gradativa, não chega a ser limitante. No rio Una ela tendeu a apresentar uma variação anual gradativa e baixa amplitude térmica, sendo homogênea na coluna d’água.

A salinidade é um dos mais importantes parâmetros ambientais a ser analisado, servindo para delimitar o início e término do estuário, como a distribuição dos organismos, sendo considerado como uma barreira ecológica para as espécies estenoalinas. Os estuários apresentam marcadas variações diurnas e sazonais nos teores de salinidade, sendo influenciadas pela ação das marés, pelo influxo de água doce proveniente dos rios e pela drenagem terrestre ocasionada pelas chuvas. Por sua vez, as espécies que habitam os estuários estão adaptadas a estas variações (BHATTATHIRI E DEVASSY, 1975). A salinidade no estuário do rio Una variou tanto em função da maré, com menores valores na baixa-mar e maiores na preamar como sazonalmente, estando mais concentrada no período de estiagem. Observou-se uma certa estratificação salina na coluna d’água. Baseado no sistema de classificação de Veneza o ambiente variou de limnético a eualino.

Já a solubilidade do oxigênio dissolvido na água varia em função da salinidade e da temperatura, estando ele mais concentrado em ambiente limnético do que nos de água salgada. Nos estuários as suas concentrações variam muito em função do fluxo e refluxo da maré. A importância na sua determinação se deve ao fato dele ser um gás essencial a vida e um indicador das condições ambientais. No estuário do rio Una, verificou-se que o teor de oxigênio dissolvido apresentou uma 
sazonalidade, havendo maior concentração no período chuvoso, devendo, este fato, estar relacionado à redução da salinidade e da temperatura da água neste período.

Macêdo e Costa (1978) classificaram o ambiente estuarino em: Zona saturada - com teores acima de 100\%; Zona de baixa saturação - com teores entre 50 e 100\%; Zona semi-poluída - com teores entre 25 e 50\%; Zona poluída - com teores abaixo de 25\%. Baseado neste sistema de classificação, verifica-se que, o estuário do rio Una enquadrou-se como zona de baixa saturação durante a baixa-mar, enquanto na preamar enquadrou-se como saturada.

De acordo com Odum (1971), o pH está diretamente ligado a quantidade de dióxido de carbono dissolvido que, por sua vez, decresce pela atividade fotossintética e aumento da respiração.

Para Flores-Montes (1996), variação diurna do pH é influenciada pelo ciclo das marés e pela taxa de fotossíntese e ou respiração, quando a primeira é a mais acentuada há um consumo de dióxido de carbono pelo fitoplâncton e os valores de $\mathrm{pH}$ acompanham o aumento do oxigênio liberado, porém no período de maior respiração há um aumento de dióxido de carbono e conseqüentemente diminuição do $\mathrm{pH}$.

O estuário do rio Una apresentou-se ligeiramente alcalino não demonstrando nenhum padrão sazonal. Tal distribuição demonstra uma certa influência marinha no ambiente e que ele se encontra dentro dos limites aceitáveis para a vida marinha estando entre 6,5 e 9,0 (Perkins, 1977). Padrão semelhante foi encontrado por Branco (2001) em Barra de Jangadas (PE), por Honorato da Silva (2003) no estuário do rio Formoso (PE) e por Grego (2004) no estuário do rio Timbó (PE).

A alta fertilidade dos estuários se deve principalmente ao aporte de água doce, aumentando assim as concentrações de sais nutrientes. Estes sais são considerados como o principal mecanismo de manutenção da fertilidade destes ambientes e das áreas costeiras adjacentes (CAVALCANTI, 1976).

Segundo Ketchum (1969), Shiroyamat et al. (1975) e Tundisi \& Tundisi (1976) os principais elementos limitantes da produção de matéria orgânica pelo fitoplâncton são o nitrogênio combinado em várias formas inorgânicas e fósforo.

No rio Una os sais nutrientes apresentaram-se de forma variável, com o nitrito e o nitrato estando mais concentrado no período chuvoso ao contrário do silicato; enquanto que o fosfato não evidenciou sazonalidade. As baixa-mares mostraram maiores teores de sais nutrientes em função do maior aporte destes sais, neste período. O silicato esteve mais concentrado seguido pelo nitrato, fosfato e nitrito. De acordo com a análise dos componentes principais o nitrito e o nitrato mostraram alta correlação direta com o material em suspensão total, a pluviometria e a biomassa fitoplanctônica e inversa com a transparência e o pH. Já o silicato apresentou correlação direta com o fosfato e inversa com a salinidade e a concentração de oxigênio dissolvido. Como observado por Feitosa (1988) na bacia do Pina (PE); Moreira (1994) no estuário do rio Cocó (CE); Honorato da Silva (2003) no estuário do rio Formoso (PE) e por Grego (2004) no estuário do rio Timbó (PE).

Devido ao forte hidrodinamismo o ambiente estuarino apresenta sempre, uma boa quantidade de material em suspensão na água. Entretanto, o regime pluviométrico da região pode provocar variação sazonal nas concentrações deste material.

O rio Una está caracterizado, na sua porção inferior, pela presença de bancos de areia resultante da ação das ondas, ventos e marés. Sazonalmente, verificou-se um aumento no período chuvoso e diminuição no período seco. Os resultados aqui obtidos são compatíveis com os verificados em outras áreas estuarinas (Feitosa, 1997 no rio Goiana (PE); Losada, 2000 nos rios Ilhetas e Mamucaba (PE) e Branco, 2001 no rio Jaboatão (PE), onde o material em suspensão total relacionou-se inversamente à altura da maré e diretamente com a pluviometria, variando apenas as concentrações obtidas entre eles).

A comunidade planctônica contribui de forma significativa para a concentração do material em suspensão total. De acordo com a UNESCO (1966), as concentrações de clorofila $a, b$ e $c$ nas amostras de água do mar, são utilizadas para estimar a biomassa e a capacidade fotossintética da comunidade fitoplanctônica. As taxas entre os vários pigmentos destas algas possibilitam indicar a 
composição taxonômica ou até o estado fisiológico da comunidade. A determinação da biomassa fitoplanctônica através da clorofila $a$, é um dos métodos mais precisos, de fácil aplicabilidade e baixo custo, além do que, é considerada uma variável que reflete a resposta do fitoplâncton às condições da água e, especialmente ao enriquecimento. Segundo Hung e Tsai (1974), normalmente uma alta concentração de clorofila $a$ indica um valor elevado de produção primária.

A biomassa algal obtidas no rio Una, caracterizou a zona estuarina, como bastante produtiva, alcançando valores mais elevados do que em outras áreas do estado de Pernambuco como Silva (1992) no estuário do rio Paripe (1,02 a 29,32mg.m ${ }^{-3}$ ); Andrade (1999) no estuário do rio Maracaípe (1,69 e 19,72mg. $\left.\mathrm{m}^{-3}\right)$; Campelo et al. (1999) na praia de Carne de Vaca (0,75 e $\left.18,94 \mathrm{mg} \cdot \mathrm{m}^{-3}\right)$; Losada (2000) no estuário dos rios Mamucaba e Ilhetas $\left(<0\right.$ a 22,2mg. $\left.\mathrm{m}^{-3}\right)$; exceto Branco (2001) no sistema estuarino de Barra das Jangadas (0,57 e 49,84mg.m ${ }^{-3}$ ).

Comparando-se o rio Una com outras áreas estuarinas tropicais verifica-se que os teores de clorofila são compatíveis em termos de sazonalidade, com valores mais altos no período chuvoso (Passavante, 1979 com o Canal de Santa Cruz (PE); Silva, 1992 com o estuário do rio Paripe (PE); Feitosa, 1997 com o estuário do rio Goiana (PE); Branco, 2001 com o sistema estuarino de Barra das Jangadas-PE) e, contrários aos obtidos por Oliveira e Passavante (1988) no estuário do rio Potengi (RN); por Feitosa et al. (1999) na Bacia do Pina (PE), quando o período seco foi mais produtivo.

Em relação à altura da maré, os teores de clorofila $a$ esteviram mais elevados durante a baixa-mar, tal como, foi observado em outras áreas estuarinas da região como, por exemplo, no rio Cocó (CE), por Moreira (1994); no estuário do rio Paripe (PE), por Silva (1992); na Bacia do Pina (PE), por Feitosa et al. (1999); e no sistema estuarino de Barra das Jangadas (PE), por Branco (2001).

\section{CONCLUSÕES}

- A precipitação pluviométrica apesar de ficar inferior em 22,58\% da média histórica dos onze anos foi suficiente para provocar modificações nos parâmetros ambientais, mostrando ainda uma relação direta com a biomassa fitoplanctônica e o material em suspensão.

- $\quad$ O estuário do rio Una variou de limnético a eualino, havendo uma certa estratificação vertical no período seco e sendo homogêneo no chuvoso.

- O teor de oxigênio dissolvido mostrou-se mais concentrado no período chuvoso, podendo-se classificar como zona de baixa saturação na baixa-mar e como zona saturada na preamar. Tornando claro que o ambiente estudado encontra-se bem suprido em oxigênio dissolvido.

- Dentre os sais nutrientes, o nitrito e o nitrato apresentaram-se mais concentrados no período chuvoso e nas baixa-mares ao contrario do silicato que esteve maior no período seco. $\mathrm{O}$ silicato foi o que esteve mais concentrado no ambiente estudado seguido pelo nitrato, fosfato e nitrito.

- A clorofila $a$ apresentou maiores concentrações no período chuvoso e na baixa-mar, sendo seus valores característicos de um ambiente eutrófico.

- Baseado na Análise dos Componentes Principais verificou-se que a clorofila $a$, nitrito, nitrato e material em suspensão mostraram uma alta correlação direta entre si e inversa com a transparência e o $\mathrm{pH}$. 


\section{REFERÊNCIAS BIBLIOGRÁFICAS}

ANDRADE, G. T. C. Biomassa fitoplanctônica do estuário do rio Maracaípe (IpojucaPernambuco). Recife, 1999. 46f. Monografia (Graduação) Universidade Federal Rural de Pernambuco.

BHATTATHIRI, P. M. A. \& DEVASSY, V. P. Effect of salinity on pigment concentrations of some tropical phytoplankters. Indian Journal of Fisheries, New Dehli 22 n.1/2, p.107-112. 1975.

BRAGA, E. S. Seasonal variation of atmospheric and terrestrial nutrients and their influence on primary production in an oligotrophic coastal system-southeastern Brazil. Revista Brasileira de Oceanografia. São Paulo, v. 47, n.1. p.47-57, 1999.

BRANCO, E. S. Aspectos ecológicos da comunidade fitoplanctônica no sistema estuarino de Barra das Jangadas (Jaboatão dos Guararapes - Pernambuco - Brasil). Recife, 2001. 125f. Dissertação (Mestrado) Universidade Federal de Pernambuco.

CAMPELO, M. J. A.; PASSAVANTE, J. Z. O. \& KOENING, M. L. Biomassa fitoplanctônica (clorofila $a$ ) e parâmetros ambientais na praia de Carne de Vaca, Goiana, Pernambuco, Brasil. Trabalhos Ocenográficos da Universidade Federal de Pernambuco. Recife, v.27, n.2, p.27-41, 1999.

CAVAlCANTI, L. B. Caracterização do Canal de Santa Cruz (PE - Brasil) em função dos parâmetros físico-químicos e pigmentos fotossintéticos. Recife, PE: 1976. 115f. Tese (Livre Docência), Departamento de Oceanografia, Universidade Federal de Pernambuco. 1976.

CONDEPE. INSTITUTO DE DESENVOLVIMENTO DE PERNAMBUCO. Secretaria de planejamento, ciência, tecnologia e meio ambiente. Perfil fisiográfico das bacias hidrográficas de Pernambuco. Recife: CONDEPE, v. I. 275p. 1980.

FEITOSA, F. A. N.; NASCIMENTO, F. C. R. \& COSTA, K. M. P. Distribuição espacial e temporal da biomassa fitoplanctônica relacionada com parâmetros hidrológicos na bacia do Pina (Recife-PE). Trabalhos Oceanográficos da Universidade Federal de Pernambuco, Recife v.27, n.2, p.1-13, 1999.

FEITOSA, F. A. N. Estrutura e produtividade da comunidade fitoplanctônica correlacionadas com parâmetros abióticos no sistema estuarino do rio Goiana (Pernambuco - Brasil). São Paulo, 1997. 250f. Tese (Doutorado) Universidade de São Paulo.

FEITOSA, F. A. N. Produção primária do fitoplâncton correlacionada com parâmetros bióticos e abióticos na Bacia do Pina (Recife - Pernambuco - Brasil). Recife, 1988. 270f. Dissertação (Mestrado) Universidade Federal de Pernambuco.

FERNANDES, M. A. A. Produtividade fitoplanctônica relacionada com alguns aspectos ecológicos no estuário do rio Congo (Itapissuma - Pernambuco). Recife, 1997. $180 \mathrm{f}$. Dissertação (Mestrado) Universidade Federal de Pernambuco.

FLORES MONTES, M J. Variação Nictimeral do fitoplâncton e parâmetros hidrológicos no canal de Santa Cruz, Itamaracá, PE. Recife, PE: 1986. 197f. Dissertação (Mestrado em 
Oceanografia Biológica), Departamento de Oceanografia, Universidade Federal de Pernambuco. 1996.

GRASSHOFF, K., EHRARDT, M., KREMELLNG, K. Methods of sea water analysis. 2 ed. New York: Verlag Chemie, 1983. 317 p.

GREGO, C. K. da S. Distribuição espacial e sazonal da composição e biomassa fitoplantônica correlacionadas com a hidrologia do estuário do rio Timbó (Paulista, Pernambuco). 2004. 117 f. Dissertação (Mestrado em oceanografia)- Departamento de Oceanografia, Universidade Federal de Pernambuco, Recife, 2004.

HONORATO DA SILVA, M. Fitoplâncton do estuário do rio Formoso (rio Formoso, Pernambuco, Brasil): biomassa, taxonomia e ecologia. 2003.131 f. Dissertação (Mestrado em Oceanografia Biológica)- Departamento de oceanografia, Universidade Federal de Pernambuco, 2003.

HUNG, T. C. \& TSAI, C. C. H. Study on chemical nutrient and photosynthetic pigments in the Kuroshio Current around Taiwan Island. Acta Oceanographica Tawanica Sci. Rep. Nat., Taiwan University. n.4, p.71-92. 1974.

KETCHUM, B.H. Eutrophication of estuarines. In: National Academy of Sciences.

Eutrophication. Proceedings of International Symposium no Eutrophication, Washington, 1969. p. 197-209.

LOSADA, A. P. M. Biomassa fitoplanctônica correlacionada com parâmetros abióticos, nos estuários dos rios Ilhetas e Mamucaba, e na Baía de Tamandaré (Pernambuco - Brasil). Recife, 2000. 89f. Dissertação (Mestrado) Universidade Federal de Pernambuco.

MACÊDO, S. J. \& COSTA, K. M. P. Estudos ecológicos da região de Itamaracá, Pernambuco Brasil. Condições Hidrológicas do Estuário do Rio Botafogo. Ciência e Cultura, São Paulo, 30 n.7, p.346-368. 1978.

MEDEIROS, C. \& KJERFVE, B. Hydrology of a Tropical Estuarine System: Itamaracá, Brazil. Estuarine, Coastal and Shelf Science. v.36, p.495-515. 1993.

MELO, U.; SUMMERHAYES, C. P. \& TORNER, L. G. Metodologia para o estudo do material em suspensão na água do mar. Boletim Técnico Petrobrás, Rio de Janeiro, v. 18, n.3/ 4, p.115-127. 1975.

MOREIRA, M. O. P. Produção do fitoplanctônico em um ecossistema estuarino tropical (Estuário do Rio Cocó, Fortaleza, Ceará). Recife, 1994. 338f. Dissertação (Mestrado). Universidade Federal de Pernambuco.

ODUM, E. P. Fundamentos de Ecologia. $4^{\circ} \mathrm{ed}$. Lisboa, Fundação Calouste Gulbekian, 1971. 927p.

OLIVEIRA, D. B. F. \& PASSAVANTE, J. Z. O. Biomassa primária do fitoplâncton do estuário do rio Potengi (Natal - Brasil). Gayana, Bot. v.45, n.1-4, p.235-240, 1988. 
PARSONS, T. R. \& STRICKLAND, J. D. H. Discussion of spectrophotometric detremination of marine plankton pigments, with revised equations of as certaining chlorophyll $a$ and carotenoids. Journal of Marine Research, New Haven, v.21, n.3, p.155-163. 1963.

PASSAVANTE, J. Z. O. Produção primária do fitoplâncton do Canal de Santa Cruz

(Itamaracá - Pernambuco). São Paulo, 1979. 188f. Tese (Doutorado) Universidade de São Paulo.

PERKINS, E. J. Inorganic Wastes In: Lenihan, J.; Fletcher, W. W. (eds.) The Marine

Environment. Glasgow: Blackie \& Son limited, 1977. p. 70-101.

SANTOS-FERNANDES, T. L. Fitoplâncton do estuário do rio Jaguaribe, (Itamaracá, Pernambuco, Brasil): ecologia, densidade, biomassa e produção. Recife, 1997. 175f. Dissertação (Mestrado). Universidade Federal de Pernambuco.

SHIROYAMAT, T.; MILLER, W.E.; GREENE, J.C. Effect of nitrogen and phosphorus on the growth of Skeletonema capricornutum. In: Proceedings bioestimulation-nutrient assessment workshop: 132-42, 1975.

SILVA, I. G. Variação sazonal e espacial da produção, biomassa e densidade fitoplanctônica no estuário do rio Paripe (Itamaracá - Pernambuco - Brasil). Recife. 1992. 153f. Dissertação (Mestrado em Botânica) Universidade Federal Rural de Pernambuco.

SOURNIA, A. Cycle annual du phytoplankton et de la production primaire dans les mers tropicales. Marine Biology, 3 n.4, p.287-303, 1969.

STRICKLAND, J. D. H. \& PARSONS, T. R. A Practical handbook of seawater analysis. 2 ed. Bulletin Fisheries Research Board of Canada, Otawa, v.167, p.207-211. 1972.

TEIXEIRA, C.; ARANHA, F. J.; BARBIERI, R. \& MELO, O. T. Produção primária e clorofila $a$ do fitoplâncton e parâmetros físicos e químicos do Estreito dos Coqueiros - Maranhão - Brasil. Revista Brasileira de Biologia. Rio de Janeiro, 48 n.1, p.29-39. 1988.

TUNDISI, J. G. \& TUNDISI, T. M. Produção orgânica em ecossistemas aquáticos. Ciência e Cultura, São Paulo, v.28, n.8, p.864-887. 1976.

UNESCO. Determination of photosyntetic pigments in sea water. Rapor of SCOR/UNESCO, working group 17 with meat from 4 to 6 June 1964. Paris: (monography on Oceanography Methodology, 1). Paris, 69 p. 1966.

UNESCO. International Oceanographic Table. Wormly, 1973. v. 2, 141 p. 